\title{
Merchandising Social como uma Estratégia de Intervenção em Metacontingências: Análise de uma Obra de Ficção Televisiva sobre o Controle do Tráfico de Pessoas no Brasil
}

\author{
Olívia Costa do Vale ${ }^{1, *}$ (D), \& Laércia Abreu Vasconcelos ${ }^{2}$ (D) \\ ${ }^{1}$ Centro Universitário UniFanor, Fortaleza, CE, Brasil \\ ${ }^{2}$ Universidade de Brasília (UnB), Brasília, DF, Brasil
}

\begin{abstract}
RESUMO - Estudos de fenômenos culturais, a partir da Análise do Comportamento, contribuem para o planejamento cultural ao utilizar estratégias como o merchandising social. O objetivo desta pesquisa foi analisar metacontingências, a partir de um tema social com forte impacto - tráfico de pessoas - em uma novela brasileira de grande audiência: Salve Jorge. As cenas relativas ao tema foram descritas em termos de contingências, classificadas em sete metacontingências, as quais foram apresentadas em alta frequência no transcorrer dos capítulos. O impacto da novela foi observado no aumento da frequência de notícias sobre tráfico de pessoas em seis jornais, além de denúncias registradas nos períodos anterior, simultâneo e posterior à exibição de Salve Jorge. As notícias são indicadores do efeito positivo da obra de ficção sobre o reconhecimento e definição de "tráfico de pessoas", o que contribuei para a frequência de denúncias em órgãos competentes e a implementação das intervenções.
\end{abstract}

PALAVRAS-CHAVE: metacontingência, merchandising social, tráfico de pessoas, práticas culturais, telenovela

\section{Social Merchandising as an Intervention Strategy in Metacontingencies: Analysis of a Work of Television Fiction about the Control of Human Trafficking in Brazil}

\begin{abstract}
Behavior-analytic studies of cultural phenomena can contribute to cultural planning by using strategies such as social merchandising. The goal of this research was to analyze metacontingencies based on a social theme of great impact - human trafficking - in a Brazilian soap opera (Salve Jorge) with a large audience. Scenes related to the theme were described in terms of contingencies, classified in seven metacontingencies, which were presented in high frequency throughout the chapters. The impact of the soap opera was observed in the increased frequency of news about human trafficking in six newspapers as well as complaints registered in the periods before, simultaneous and after the exhibition of Salve Jorge. The news is indicative of the positive effect of a work of fiction on the recognition and definition of "human trafficking", which also contributes to a higher frequency of complaints and interventions implemented by competent agencies.
\end{abstract}

KEYWORDS: metacontingency, social merchandising, human trafficking, cultural practices, soap opera

Investigações sobre contingências sociais ou, alternativamente, análises funcionais de fenômenos culturais complexos têm sido amplamente desenvolvidas por analistas do comportamento desde a década de 1980, principalmente por meio do conceito de metacontingência (Lamal \& Greenspoon, 1992). O termo evoluiu ao longo das últimas três décadas e é utilizado para descrever relações entre classes de operantes que produzem consequências

*E-mail: ovale@fanor.edu.br

- Submetido: 25/08/2016; Aceito: 18/02/2018. 
individuais em relações definidas por meio de contingências tríplices. Essas contingências podem ocorrer de forma interdependente e recorrente, sendo denominadas de contingências comportamentais entrelaçadas (CCEs), e produzem efeitos, denominados de produtos agregados (PAs), que vão além das consequências individuais presentes em cada uma delas. As contingências comportamentais entrelaçadas e o produto agregado são selecionados por uma consequência cultural (CSQ Cultural) em um ambiente externo (Glenn, 1986, 1988, 2004; Glenn \& Malott, 2004; Glenn et al., 2016; Vasconcelos, 2013; Vasconcelos \& Lemos, 2018).

Um conjunto significativo de pesquisas experimentais (e.g., Baia, Azevedo, Segantini, Macedo, \& Vasconcelos, 2015; Soares, Rocha, Guimarães, Leite, Andery \& Tourinho, 2018; Vasconcelos, 2013; Vichi et al., 2009) e não-experimentais foi desenvolvido na última década (e.g., Cabral \& Todorov, 2016; Fonseca \& Vasconcelos 2013; Kill, 2016; Sénéchal-Machado \& Todorov, 2008), sobre o conceito de metacontingência, demonstrando sua utilidade para interpretação de fenômenos sociais e para o planejamento de futuras intervenções em práticas culturais. Essa unidade de análise permite estudar a atuação dos indivíduos em grupos de forma a identificar produções agregadas e consequências culturais. Ainda, essa unidade pode ser utilizada para investigar tanto fenômenos menos complexos, como a interação entre duas pessoas em um ambiente restrito, quanto práticas culturais de uma sociedade (Tourinho \& Vichi, 2012).

O estudo da cultura em uma abordagem analíticocomportamental que utiliza o conceito de metacontingência destaca a linhagem culturo-comportamental: a transmissão do comportamento operante por meio de repertórios individuais (Glenn et al., 2016). Metacontingências são o foco do estudo de sistemas comportamentais (e.g., governo, economia, educação, saúde, religião e mídias) e envolvem análises de redes verbais que compõem a transmissão de práticas culturais (ver Houmanfar \& Mattaini, 2018; Vasconcelos, Nogueira, Vieira, \& Henz, no prelo). Ao se estudar intervenções em práticas culturais é necessário discutir também os grupos envolvidos nessas práticas. Skinner (1953/2003) afirmou que as culturas humanas são ambientes sociais complexos, mas, em geral, desorganizados, sendo necessária a criação de agências controladoras para organizar a convivência entre indivíduos e gerenciar seus comportamentos. Essas agências exercem controle sobre o grupo a partir do poder de reforçar ou punir, manipulando um conjunto de variáveis de forma a controlar, direta e indiretamente, o comportamento dos indivíduos envolvidos. O governo, a economia, a educação, a religião e a psicoterapia são exemplos de agências controladoras. A mídia também corresponde a uma agência de controle. Ao deter o reforçador 'informação', controla o comportamento dos indivíduos de uma sociedade, divulgando informações sobre a realidade e construindo um conhecimento socialmente produzido (Martone \& Banaco, 2005).

A construção social do conhecimento seria uma análogo analítico-comportamental para as representações sociais da psicologia social. Grande parte do que um indivíduo conhece sobre o mundo é socialmente construído, ou seja, mediado por outras pessoas. Dessa forma, o conhecimento do homem sobre o mundo pode ocorrer por meio do contato com as contingências (saber como) ou por meio das descrições fornecidas pela comunidade verbal (saber que). Este segundo tipo de conhecimento necessariamente envolve a mediação de outros indivíduos, sendo um conhecimento socialmente construído, pois são visões do mundo mantidas por reforços oferecidos pela comunidade verbal (Guerin, 1992).

Ao considerar as redes de interação a partir das mídias, no cenário contemporâneo, verifica-se instrumentos de comunicação cada vez mais sofisticados e eficientes que permitem a transmissão de informação em segundos para uma expressiva quantidade de pessoas e países, nos diferentes continentes. Houve uma expansão do número de usuários e um processo de concentração de poder da mídia em um pequeno número de corporações. Os grandes conglomerados de mídia, no processo de divulgação de informação, mantêm laços estreitos com o Estado, com implicações nas áreas política e econômica, o que resulta em alto poder de influência sobre a sociedade (Friedman, 2009; Goulart, 2018; Laitinen \& Rakos, 1997; Harari, 2018; Martone \& Banaco, 2005).

As sociedades contemporâneas têm contato com muitos dos acontecimentos cotidianos de vários locais do mundo por meio de veículos da mídia. E, quando um indivíduo fica sob controle da realidade construída, as possibilidades de contato direto com o ambiente real são reduzidas, aumentando a possibilidade de que a mídia ganhe espaço de interferência sobre as formas de ver e pensar a realidade (Alves, 2006). Há o risco de meios de comunicação de ampla divulgação assumirem um caráter alienante, uma vez que a reprodução de alguns discursos perpetuados por essas agências é mantida pelo reforçamento social de certos grupos e não por sua correspondência com o ambiente (Ferreira, 2009).

Devido a essas possibilidades de controle, observa-se, nas últimas décadas, um grande número de estudos, em diferentes áreas do conhecimento, voltados para a influência da mídia sobre o comportamento de diferentes grupos sociais, uma vez que essa instituição tem gradativamente modificado a ordem econômica, social e cultural da sociedade contemporânea (Ferreira, 2009; Giannotti, 2009; Harari, 2018). Além disso, sugere-se que seria possível utilizar uma tecnologia de ampla divulgação para intervir nas práticas culturais de tal forma a se obter mudanças no comportamento em larga escala, alcançando grande número de pessoas. Esse tipo de intervenção é especialmente importante quando o comportamento alvo representa não só problemas para alguns indivíduos, como também para sociedade (Glenn \& Malagodi, 1991). 
Uma vez que a mídia influencia práticas sociais dos cidadãos, ela poderia funcionar como uma estratégia para disseminar práticas culturais ou para modificá-las, a partir de macrocomportamentos em macrocontingências ${ }^{1}$ e/ou linhagens culturo-comportamentais em metacontingências. Um estudo analítico-comportamental das funções controladoras da mídia possibilitará construir ferramentas para modificar macrocomportamentos (práticas culturais) de risco (Laitinen \& Rakos 1997).

Macrocomportamento é definido como "comportamento operante socialmente aprendido observado no repertório de vários/muitos membros de um sistema cultural" (Glenn et al., 2016, p. 18). Portanto, em macrocontingências observase a independência funcional entre as contingências que a compõe, resultando em um produto acumulado. Porém, sem um ambiente único seletivo dessas relações e produto social. Em metacontingências, a matriz envolve o culturante (CCEs $\rightarrow$ PA), o qual é selecionado por um ambiente seletivo comum. Metacontingência é definida como "uma relação contingente entre: 1) contingências comportamentais entrelaçadas recorrentes que têm um produto agregado e 2) ambiente seletivo, eventos ou condições." (Glenn et al., 2016, p.13)

Ao utilizar mídias com estratégias voltadas para mudanças comportamentais, emissoras em diversos países utilizam programas de entretenimento para divulgar mensagens educacionais para as audiências. Assim, alguns programas da mídia tornaram-se instrumentos para incentivar a cidadania e contribuir para a comunidade. Propostas como estas têm sido implementadas frequentemente por meio de telenovelas, séries e minisséries dramáticas (Agência de Notícias dos Direitos da Infância, 2004; Singhal, Cody, Rogers \& Sabido, 2008).

Um dos principais modelos de educação e/ou mobilização por meio de ficções audiovisuais é o merchandising social, que funciona como uma estratégia parcial e pontual por meio de inserção de temas sociais e mensagens de mobilização no contexto de uma história ficcional, como, por exemplo, uma telenovela. Essa estratégia de comunicação transmite mensagens com um caráter socioeducativo, oferecendo à audiência um conjunto de informações que possibilita análises mais amplas de um conteúdo alvo de forma a difundir conhecimento, promover novos valores e princípios éticos, críticas sociais, estimular mudanças de comportamentos e incentivar o debate de questões de relevância social por meio de enredos de programas de entretenimento (Agência de Notícias dos Direitos da Infância, 2004; Desidério, 2013; Lopes, 2009; Schiavo, 1998, 2002, 2007).

$1 \mathrm{O}$ termo práticas culturais é amplamente definido a partir de crenças e atitudes, e aqui é substituído por macrocomportamento (comportamento operante com similaridades topográficas entre vários indivíduos). Assim, macrocomportamentos podem estar organizados em macrocontingências. Enquanto que, em metacontingências, há recorrência e seleção de linhagens culturo-comportamentais (ver Glenn et al., 2016).
O merchandising social no Brasil é frequentemente inserido em telenovelas, como uma estratégia educativa. As telenovelas existem há quase tanto tempo quanto a televisão no Brasil. Nos últimos 50 anos, elas têm acompanhado as mudanças tecnológicas, políticas, sociais e culturais que marcaram a história do país, tornando-se um dos programas de mais alta audiência no país de acordo com o Instituto Brasileiro de Opinião Pública e Estatística (Ibope ), desde a década de 1970 (Hamburger, 2000).

Diversas novelas da Rede Globo utilizaram o merchandising social para desenvolver temáticas de alto impacto para a sociedade brasileira. É possível citar alguns exemplos de intervenções bem-sucedidas, como o caso da novela Laços de Família, com o tema doação de medula (Shiavo, 2002), e Páginas da Vida, com o planejamento familiar (Shiavo, 2007). Entretanto, deve-se considerar que a estratégia do merchandising social também pode propagar padrões comportamentais defendidos pela indústria da qual o merchandising social tem sua origem, promovendo a manutenção do status quo (Ali, 2008).

A telenovela de Glória Perez, Salve Jorge, exibida pela emissora Rede Globo de Televisão, trouxe, por meio do merchandising social, informações sobre tráfico de pessoas, contribuindo para discussões acerca da temática produzidas pelas campanhas de combate ao crime (e.g., Campanha da Fraternidade de 2014; Campanha Coração Azul) e, para discussões voltadas para alterações recentes no Código Penal brasileiro em relação a essa prática (Venson \& Pedro, 2013).

$\mathrm{O}$ tráfico de pessoas é considerado um dos maiores problemas da sociedade do século XXI, sendo a terceira modalidade criminosa mais lucrativa no mundo. A International Labour Office (ILO, 2017) estima que 225 milhões de vítimas de trabalho forçado e 4,8 milhões de pessoas foram vítimas de exploração sexual em 2016. Diante dessa estatística alarmante, o tema necessita de discussões em todos os continentes (Ministério da Justiça, 2012).

O crime de tráfico de pessoas é definido pelo Protocolo Adicional à Convenção das Nações Unidas contra a Criminalidade Organizada Transnacional relativo à Prevenção, Repressão e Punição do Tráfico de Pessoas, em especial de Mulheres e Crianças como:

[...] O recrutamento, o transporte, a transferência, o alojamento ou o acolhimento de pessoas, recorrendo à ameaça ou ao uso da força ou a outras formas de coação, ao rapto, à fraude, ao engano, ao abuso de autoridade ou de situação de vulnerabilidade ou à entrega ou aceitação de pagamentos ou benefícios para obter o consentimento de uma pessoa que tem autoridade sobre outra, para fins de exploração. A exploração deverá incluir, pelo menos, a exploração da prostituição de outrem ou outras formas de exploração sexual, o trabalho ou serviços forçados, a escravatura ou práticas similares à escravatura, a servidão ou a extração de órgãos. (UNODC, 2000, p. 2)

Arruda, D’Urso, Kodama e Armede (2013) destacam que a falta de conhecimento da sociedade sobre a existência 
e as formas de configuração desse crime contribuem para a manutenção e desenvolvimento desse delito, bem como para a baixa frequência de denúncias. Assim, uma forma de intervenção para o combate ao tráfico de pessoas é a divulgação de contingências comportamentais com: (1) os comportamentos envolvidos no tráfico de pessoas; (2) as consequências que mantêm ou enfraquecem tais ações; e (3) as ações de enfrentamento.

Em seu enredo, a telenovela Salve Jorge promoveu a discussão de alguns desses aspectos, em diferentes metacontingências que incluíram a própria gestão da organização criminosa, a luta de familiares que tiveram parentes desaparecidos, o combate por parte dos operadores da lei e o envolvimento de pessoas com a organização, desconhecendo as práticas criminosas. A novela possibilitou a difusão de informações, com contingências que evocaram comportamentos relacionados ao tema em diferentes segmentos da sociedade, promovendo prevenção e o combate desse crime no Brasil, a partir das estratégias de merchandising social.

Portanto, pesquisas sobre a efetividade do merchandising social em evocar determinados comportamentos favoráveis à sociedade no contexto de apresentação de determinados temas, a significativa utilização de novas mídias de tela no século XXI e o estudo da evolução e seleção de práticas sociais pela Análise do Comportamento ocasionaram o presente estudo. Dessa forma, o objetivo geral deste trabalho foi analisar as metacontingências envolvidas na apresentação de um tema social de alto impacto, o tráfico de pessoas, inserido em uma novela de alta audiência (Salve Jorge).

\section{MÉTODO}

Uma pesquisa documental foi desenvolvida, a partir da análise das metacontingências, envolvendo personagens e tramas relativos ao crime de tráfico de pessoas na novela Salve Jorge, escrita por Glória Perez, e exibida pela Rede Globo de Televisão entre outubro de 2012 e maio de 2013. Cento e setenta e cinco dos 179 capítulos foram disponibilizados pelo Departamento de Justiça, Classificação, Títulos e Qualificação do Ministério da Justiça. Apenas os quatro primeiros capítulos não foram analisados por não constarem no banco de dados.

Inicialmente, registrou-se o número do capítulo, a data de exibição, os pontos de audiência para cada capítulo da novela, a duração de cada capítulo (com intervalos comerciais) e a duração de cada cena que se referia ao tema de interesse. Cada cena associada ao crime de tráfico de pessoas foi descrita da forma que foi exibida. Compilou-se a duração de cenas para cada capítulo de forma que foi possível analisar quanto do episódio foi dedicado ao merchandising social, voltado para o tráfico de pessoas, e o tempo de exposição da audiência ao tema. Selecionaram-se para análise todas as cenas em que continham o tema tráfico de pessoas. A partir desses dados, comparou-se a quantidade de cenas relacionadas ao tema social e os pontos de audiência de cada capítulo.

As cenas relacionadas ao tráfico de pessoas foram analisadas funcionalmente e descritas de acordo com os contextos exibidos, agentes em cena, comportamentos observados e suas consequências. Em seguida, sete metacontingências foram descritas, como mostra a Tabela 1.

Tabela 1

Metacontingências no tráfico de pessoas da novela Salve Jorge

\begin{tabular}{|c|c|c|}
\hline Metacontingência & Título & Descrição \\
\hline 1 & $\begin{array}{l}\text { Organização/Empresa } \\
\text { de Tráfico de Pessoas }\end{array}$ & $\begin{array}{l}\text { Contingências que estão diretamente ligadas ao gerenciamento da organização de tráfico de pessoas, } \\
\text { envolvendo as interações dos membros da organização cumprindo suas funções e solucionando } \\
\text { problemas. }\end{array}$ \\
\hline 2 & $\begin{array}{l}\text { Tráfico de jovens para } \\
\text { exploração sexual }\end{array}$ & $\begin{array}{l}\text { Contingências que envolvem interações entre jovens traficadas para a exploração sexual, entre } \\
\text { jovens e clientes e entre jovens e traficantes, antes ou depois de serem traficadas. Contingências } \\
\text { que envolvem tentativas de fugas e ações de combate à organização de tráfico por parte das jovens } \\
\text { traficadas. }\end{array}$ \\
\hline 3 & Líderes do tráfico & $\begin{array}{l}\text { Contingências envolvendo as ações da liderança do tráfico para proteger a organização e evitar a } \\
\text { ações policiais. Consequências dessas ações para vítimas. }\end{array}$ \\
\hline 4 & $\begin{array}{l}\text { Tráfico de crianças } \\
\text { para adoções ilegais }\end{array}$ & Contingências envolvendo o roubo, compra e venda de crianças para a adoção ilegal. \\
\hline 5 & $\begin{array}{l}\text { Ações dos membros } \\
\text { da organização em } \\
\text { benefício próprio }\end{array}$ & $\begin{array}{l}\text { Contingências envolvendo os membros da organização atuando para obter lucros e benefícios dentro } \\
\text { e fora da organização. }\end{array}$ \\
\hline 6 & $\begin{array}{l}\text { Ações de familiares, } \\
\text { amigos e de terceiros }\end{array}$ & $\begin{array}{l}\text { Contingências envolvendo as ações de investigação e combate ao tráfico de pessoas e proteção das } \\
\text { vítimas por parte dos familiares, amigos das vítimas e terceiros. }\end{array}$ \\
\hline 7 & $\begin{array}{l}\text { Ações de operadores } \\
\text { da lei }\end{array}$ & $\begin{array}{l}\text { Contingências envolvendo as ações investigativas da polícia e outros agentes relacionados ao Direito } \\
\text { para o combate ao tráfico de pessoas. }\end{array}$ \\
\hline
\end{tabular}


As metacontingências contaram com a identificação dos participantes, contingências comportamentais entrelaçadas (CCEs), produtos agregados (PAs) e possíveis consequências culturais com função de selecionar os culturantes (CCEs $\rightarrow$ PAs), de forma a operacionalizar como a temática foi apresentada para a audiência e quais aspectos do tráfico de pessoas foram discutidos ao longo da novela. A partir da ocorrência de cada uma das sete metacontingências, foi atribuído o número 1 para a ocorrência de cada metacontingência em um capítulo, e o número 0 para a não ocorrência. Essa medida possibilitou verificar quais metacontingências tiveram maior ocorrência e como essas se distribuíram ao longo da novela.

Após essas análises, investigou-se o impacto da inclusão do tema, via merchandising social, em uma novela de alta audiência, sobre o controle do tráfico de pessoas no país. Verificou-se o número de denúncias feitas à Central de atendimento à Mulher (Ligue 180) nos períodos anterior, simultâneo e posterior á exibição da novela, a partir dos dados obtidos pelos balanços gerais publicados pela Secretaria de Política para as Mulheres (2012, 2013, 2015a, 2015b). Verificou-se também a veiculação de notícias em jornais (Correio Braziliense, O Globo, Folha de São Paulo, O Estado de São Paulo e Valor Econômico) nos períodos anterior, simultâneo e posterior à exibição da novela. Os dados foram obtidos na pesquisa Tráfico de Pessoas na Imprensa, realizada pelo Departamento de Enfrentamento ao Tráfico de Pessoas do Ministério da Justiça em parceria com a ONG Repórter Brasil (Ministério da Justiça 2014).

\section{RESULTADOS}

Os 175 capítulos analisados tiveram uma duração média de $67 \mathrm{~min}$ e $14 \mathrm{~s}(\mathrm{DP}=0,0073)$, estando inclusos nessa contagem os períodos de intervalos comerciais. O capítulo 179, exibido em 17 de maio de 2013, foi o mais longo, com a duração de 95 min e 49 s. O capítulo 99, exibido em 13 de fevereiro de 2013, foi o mais curto, com a duração de 42 min e $4 \mathrm{~s}$. Os capítulos mais curtos frequentemente foram exibidos nas quartas-feiras em decorrência da exibição subsequente dos jogos do Brasileirão Série A, no período de 19 de maio a 2 de dezembro 2013.

A Figura 1 apresenta os pontos de audiência registrados para cada capítulo, no transcorrer da novela, e a duração do capítulo dedicada às cenas de tráfico de pessoas. Em média, 24 min de cada capítulo apresentavam cenas sobre o tema de interesse $(1396,60 \mathrm{~s}$; $\mathrm{DP}=573,91)$. O capítulo 27 , exibido em 21 de novembro de 2013, teve o menor tempo dedicado ao tema, apenas $4 \mathrm{~min} 32 \mathrm{~s}$, enquanto o capítulo 169, exibido em 6 de maio de 2013, teve o maior tempo dedicado ao tema, com 56 min 26 s. A média de audiência da novela foi de 33,99 pontos $(\mathrm{DP}=4,99)$, sendo um ponto de audiência equivalente a 608.165 domicílios e 204.107 indivíduos no Painel Nacional de Televisão (PNT) (IBOPE reajusta, 2014). O capítulo 179 , exibido em 17 de maio de 2013 , teve a maior audiência, como 46 pontos, enquanto o capítulo 61, exibido no dia 31 de dezembro de 2012, teve a menor audiência, com 18 pontos.

A cada capítulo comparou-se a duração das cenas de tráfico com os pontos de audiência. A partir da análise visual das linhas de tendências, observa-se, nos capítulos 1 a 45 (painel superior esquerdo), uma diminuição na audiência e um aumento na duração das cenas. Nos capítulos 46 a 90 (painel superior direito) houve aumento na audiência, enquanto a duração das cenas permaneceu estável (faixa de variação entre 1000 s a 1500 s). Nos capítulos 91 a 135 (painel inferior esquerdo), tanto a audiência (entre 36 e 39 pontos) quanto a duração das cenas (entre 1500 s e 2000 s) permaneceram estáveis. Finalmente, nos capítulos 136 a 179 houve aumento na audiência e na duração das cenas de tráfico de pessoas.

A duração das cenas de tráfico de pessoas em cada capítulo aumentou ao longo da novela, sendo o capítulo 40, exibido no dia 6 de dezembro de 2012, o ponto de transição do aumento da frequência e duração das cenas. Nos capítulos anteriores a este ponto de transição, a exibição de cenas do tráfico de pessoas era de 4 a 12 cenas por capítulo, com uma duração média de 13 min $38 \mathrm{~s}$ por capítulo. No entanto, após o capítulo 40, a frequência aumentou para 6 a 20 cenas por capítulo, e a duração média das cenas aumentou para 26 $\min 23 \mathrm{~s}$.

A Figura 2 mostra a frequência acumulada das sete metacontingências ao longo dos capítulos da novela. Observa-se que as metacontingências 2 (Tráfico de jovens para exploração sexual), 1 (Organização/Empresa de Tráfico de Pessoas), 7 (Ações de operadores da lei) e 3 (Líderes do tráfico) apresentaram as maiores frequências de ocorrência durante a novela, respectivamente. As metacontingências 2 , 1,7 e 3 estiveram presentes respectivamente em $98,28 \%$, $87,42 \%, 82,85 \%$ e $71,42 \%$ dos capítulos analisados. A metacontingência 4 (Tráfico de crianças para adoção ilegal) esteve presente em $64,57 \%$ dos capítulos analisados. A metacontingência 5 (Ações de membros da organização em benefício próprio) foi identificada em $65,14 \%$ dos capítulos analisados, e a metacontingência 6 (Ações de familiares, amigos e de terceiros) apresentou a menor frequência (62,28\% dos capítulos analisados).

Apesar de ter um crescimento constante nos 70 primeiros capítulos, apresentando uma frequência de ocorrência até mais alta do que a metacontingência 7 nesse bloco de capítulos, observou-se uma diminuição da frequência da metacontingência 4 a partir do capítulo 76 . O mesmo aconteceu com a metacontingência 3 , cuja frequência cresceu de forma quase constante até o capítulo 123 e, em 
seguida, observou-se uma diminuição de ocorrência nos capítulos seguintes. A metacontingência 7 teve sua primeira ocorrência no capítulo 15 e apresentou pausas frequentes até o capítulo 46. Após este momento, a metacontingência
7 aumentou de forma constante e, a partir do capítulo 124, esteve presente em todos os capítulos até o final da novela.

AFigura 3 apresenta um diagrama para a metacontingência 1, intitulada de Organização/empresa de tráfico de pessoas.
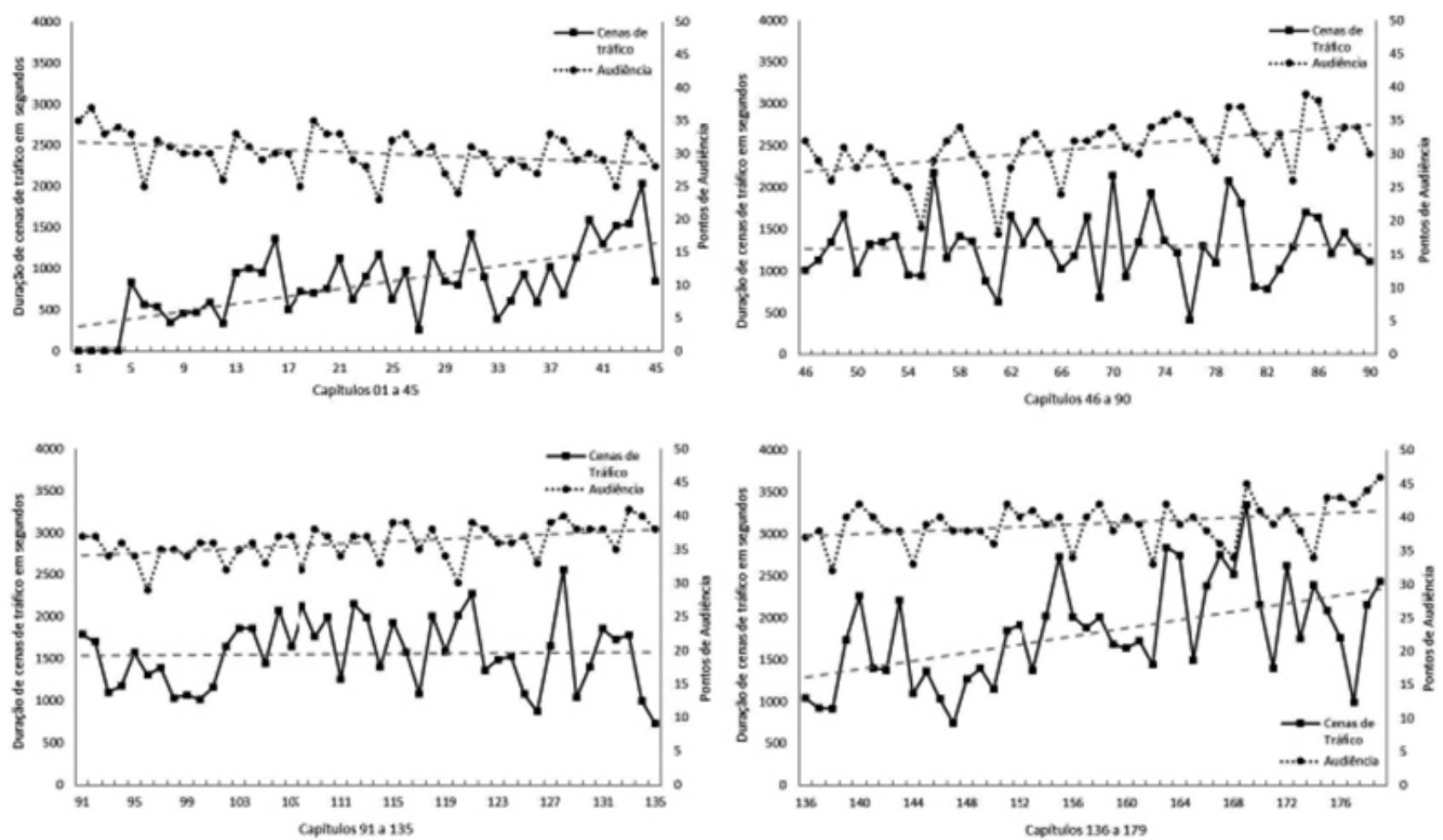

Figura 1. Comparação entre pontos de audiência e duração das cenas de tráfico de pessoas para 179 capítulos da novela Salve Jorge.

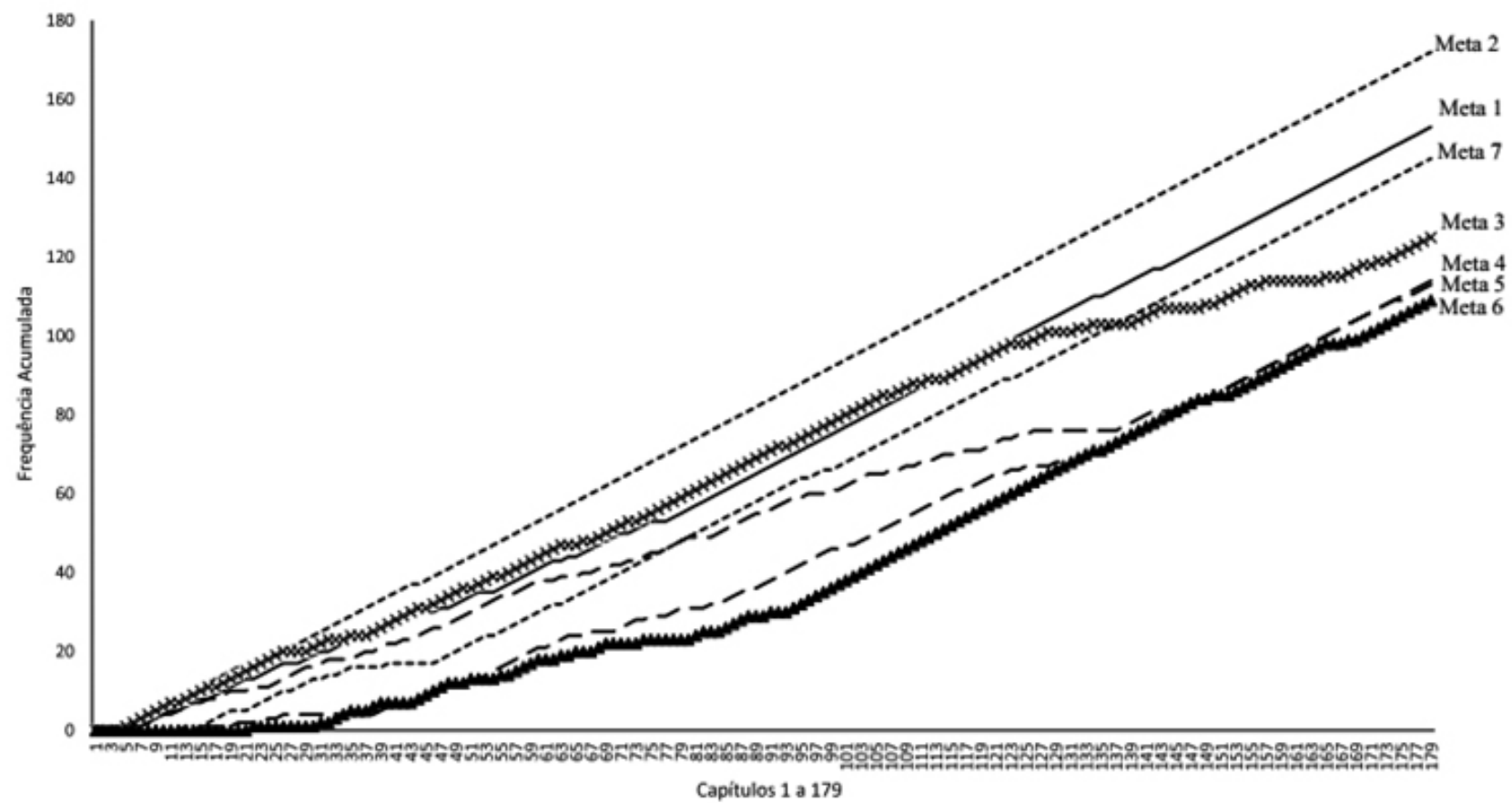

Figura 2. Registro cumulativo de ocorrência das metacontingências 1) Organização/Empresa de Tráfico de Pessoas; 2) Tráfico de jovens para exploração sexual; 3) Líderes do tráfico; 4) Tráfico de crianças para Adoções ilegais; 5) Ações dos membros da organização em benefício próprio; 6) Ações de familiares, amigos e de terceiros; 7) Ações de operadores da lei, ao longo de 179 capítulos da novela. 
Essa metacontingência recebeu destaque (segunda metacontingência com maior frequência de apresentação) na novela, uma vez que buscava descrever as contingências comportamentais envolvidas no crime de tráfico de pessoas para sua audiência. Grande parte do enredo foi dedicado à atuação dessa organização. Foram apresentadas aos espectadores cenas sobre a administração da organização, os PAs a serem obtidos, as CCEs envolvendo os criminosos, vítimas e seus familiares, operadores da lei, e novos integrantes que são inseridos na organização sem saberem do tráfico de pessoas. E, ainda, como a organização pode se proteger de ameaças tanto de ações policiais, das vítimas e seus familiares, assim como de organizações concorrentes.

É possível interpretar os dados da Figura 3, com os quatro conjuntos de entrelaçamentos (CCEs) e seus respectivos resultados (PAs), de forma a compor duas metacontingências: (a) CCEs envolvem a jovem traficada, um cliente e gerentes da boate. $O$ resultado desta tentativa de denúncia pela jovem foi receber punição individual de alta magnitude e, ainda, o fortalecimento da proteção da rede criminosa entre países que mantinha aquela boate. (b) Nessa rede de relações, participou também a líder do tráfico desta organização que sai do Brasil para verificações junto à gerência da boate em Madri; (c) CCEs com agentes brasileiros selecionam "novos talentos" por meio de fotografias de jovens que serão introduzidas, sem conhecimento prévio, na boate de exploração sexual. O PA envolve o sucesso na renovação e aumento de jovens traficadas para a boate em Madri. (d) Nessa rede de interações voltada para a seleção de jovens, o PA é também representado por lucro da organização e da rede internacional de tráfico de pessoas. Assim, um PA alvo principal é composto por: (1) aumento de jovens traficadas; (2) sequestro e tráfico de crianças; (3) adoção ilegal, e (4) proteção fortalecida da rede criminosa. Como ambiente selecionador comum para essas CCEs $\rightarrow$ PAs, estão os clientes que financiam a exploração sexual, por exemplo, revertendo para a organização criminosa o lucro ao ano de 32 bilhões sob controle dos líderes da organização. Por modelação, a organização criminosa é valorizada e admirada como modelo de sucesso no contexto do crime.

A Metacontingência 1 pode ser classificada como cerimonial e conservadora (Todorov, 2017) pois grande parte de seus reforçadores são sociais, diretamente ligado às figuras de liderança. É o status e a autoridade dessa liderança que mantêm a metacontingência cerimonial (ver Glenn, 1986). As CCEs são mantidas principalmente por regras rígidas e pela ameaça de punição caso não sejam cumpridas.

Essa metacontingência também está diretamente ligada com a Metacontingência 5, que trata das ações dos membros da organização atuando para obter lucros e benefícios dentro e fora da organização. Os agentes Russo, Irina e Wanda apresentam ações que são frequentemente realizadas sem a aprovação da liderança da organização com o objetivo de obter lucros individuais. Rosângela também é uma das principais agentes dessa metacontingência. A jovem traficada torna-se cúmplice dos seus traficantes, evitando punições e obtendo lucros de forma consistente com a organização. Posteriormente, a líder Lívia também utiliza recursos da organização em benefício próprio. O produto agregado da Metacontingência 5 é o lucro individual proporcionado por

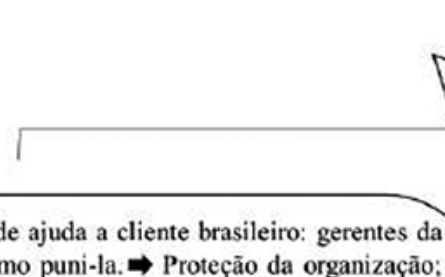

Jovem traficada pede ajuda a cliente brasileiro: gerentes da manutenção de controle sobre as jovens traficadas.

Jovem traficada é punida por pedir ajuda: Lider do tráfico viaja para Madri para avaliar boate. $\Rightarrow$ Fiscalização dos funcionários para proteção da organização e conferência de lucros.

Jovens participam da seleção de talentos: Líderes do tráfico selecionam garotas à serem traficadas a partir de fotografias. $\Rightarrow$ Aquisiçào de novas jovens para a boate de exploração sexual.

Aquisição de novas jovens para exploração sexual: Jovens são levadas para boate. $\Rightarrow$ Geração de mais lucros para organização.

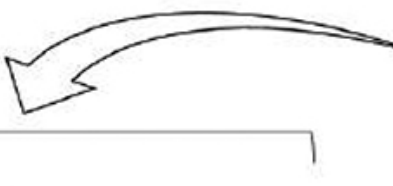

\section{西}

Contingências Comportamentais Entrelaçadas (CCEs)

\section{Jovens adquiridas} para exploração sexual e crianças adquiridas para adoção ilegal; Proteção da Organização;

Produto Agregado (PA)
Consumo dos serviços pelos clientes (Lucro de 32 bilhões ao ano); Valorização da Organização frente a outras organizações de tráfico de pessoas

Figura 3. Metacontingência 1 - Organização de tráfico de pessoas. 
essas ações, no entanto o lucro é também acompanhado por riscos e enfraquecimento da organização. As consequências culturais são disponibilizadas pela líder na escala mais alta da hierarquia ao punir tais práticas dos agentes envolvidos.

As buscas de lucros paralelas à organização são toleradas apenas se não lhe forem prejudiciais, como é caso de um dos personagens de forte apoio da liderança criminosa, Wanda, enganar um militar, o personagem Coronel Nunes para obter dinheiro. Entretanto, se a busca por lucros individuais concorrer com os lucros ou com a segurança do grupo como a venda da jovem Waleska para outra organização e a chantagem da agente Wanda com uma mãe para a qual havia sequestrado um bebê e feito adoção ilegal (personagem Berna) - a liderança pune os agentes responsáveis (e.g., o personagem Wanda) e as atividades são encerradas (e.g., venda de jovens para exploração sexual para outras organizações e extorsão de uma mãe que havia compactuado com sequestro e adoção ilegal de um bebê). Entretanto, quando o agente que busca esses benefícios é a própria líder, a punição é fornecida pelos membros da organização à medida que tentam usurpar o cargo da liderança.

A Figura 4 apresenta a Metacontingência 2, que se refere ao Tráfico de jovens para a exploração sexual. Essa foi a metacontingência com maior frequência na novela e teve a função de esclarecer que a exploração sexual é uma das principais finalidades para o tráfico de pessoas e que as jovens na boate são vítimas de um crime, independentemente de terem sido enganadas com propostas de trabalho tradicionais ou de terem recebido ofertas para prostituição.
Todas foram tiradas de suas famílias e do Brasil, mantidas em cárcere privado e forçadas a trabalhar para o lucro do grupo de tráfico. Essas relações caracterizam o crime de tráfico, de acordo com a definição da ONU (2000). Entretanto, na novela nomeou-se equivocadamente a exploração sexual sofrida pelas personagens de "prostituição", a qual é uma profissão reconhecida pelo Ministério do Trabalho no Brasil.

Os principais agentes da Metacontingência 2 são as jovens traficadas, com destaque para quatro personagens: Morena, Jéssica, Waleska e Rosângela; os traficantes que interagem diretamente com as jovens, três personagens que mantêm contato direto com a líder da organização Russo, Irina e Wanda; clientes e outros funcionários da boate, com destaque para o personagem Adam, que atende aos gerentes da boate. A Figura 4 mostra dois painéis com CCEs que produzem PAs opostos: no painel superior, lucro do serviço de exploração da boate e, no painel inferior, riscos para a organização em forma de denúncias pelos familiares das jovens traficadas, processos de investigação policial e proteção das famílias para outros jovens em situação de risco. Portanto, no primeiro bloco de CCEs com PA em forma de lucro para a organização, interações das jovens relacionadas ao não cumprimento de regras resulta em punição física aplicada pelos gerentes da boate, assim como a tentativa de fuga seguida pela recaptura. No segundo bloco de CCEs com PA, representado pela fragilidade da organização, as CCEs mostram o sucesso da fuga de uma jovem e suas interações via mídias oferecendo descrições detalhadas das atividades criminosas para agentes policiais.
Instruções dos gerentes da boate para se comportar na boate: jovem traficada se recusa a seguir as regras. $\Rightarrow$ É agredida fisicamente por gerente da boate;

Agressão de uma das jovem traficada: outras vitimas lhe repreendem por desobedecer as regras. $\Rightarrow$ Esquivam-se de também serem punidas pelos gerentes da boate.

Ausência de seguranças no prédio do alojamento: jovens traficadas tentam fugir do cativeiro. $\Rightarrow$ São recapturadas.

Recaptura das jovens traficadas: gerente da boate pune-as com agressões fisicas. $\Rightarrow$ Evita novas tentativas de fuga.

Distração do gerente da boate: jovem traficada foge. $\Rightarrow$ Afasta-se do contexto aversivo no qual estava inserida.

Fuga da jovem traficada: gerente da boate organiza grupo de busca. $\Rightarrow$ Prejuízos pela perda da jovem.

Fuga da jovem traficada: jovem traficada fornece informações sobre a boate a polícia. $\Rightarrow$ Auxílio as investigações dos operadores da lei.

Contingências Comportamentais Entrelaçadas (CCEs)

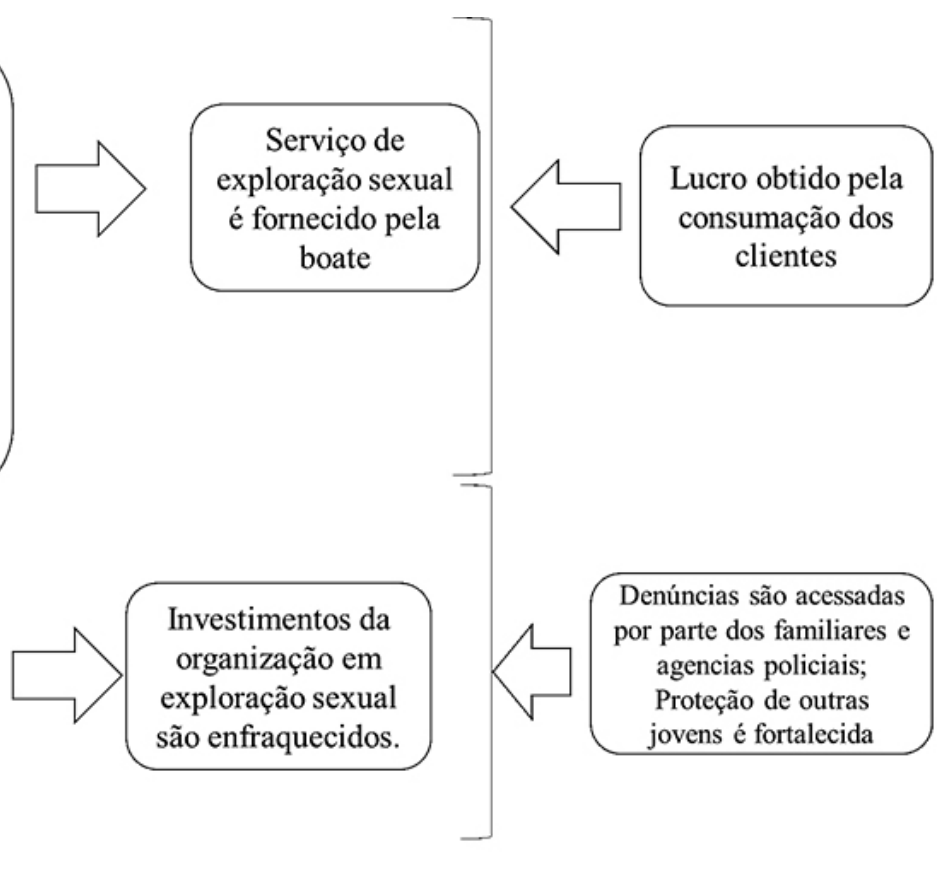

Produto Agregado (PA) Consequências Culturais (CC)

Figura 4. Metacontingência 2 - Tráfico de jovens para exploração sexual. 
A consequência cultural selecionadora para esses culturantes é disponibilizada pelas famílias das jovens traficadas, mídias e operadores da lei diante das denúncias, fortalecendo a proteção de jovens contra esse crime, aumentando as operações policiais contra os criminosos.

A novela Salve Jorge também buscou destacar que os envolvidos no crime de tráfico de pessoas podem estar integrados na sociedade, com trabalhos lícitos que disfarçam suas atividades ilícitas. Essas CCEs são apresentadas na Metacontingência 3, com líderes influentes na sociedade, envolvendo novos sócios, os quais desconhecem que a empresa tem como fonte a exploração sexual. Os principais agentes dessa metacontingência são a líder principal da organização e sua agente de alta confiança, os personagens Lívia e Wanda, com participações ocasionais de dois agentes principais da boate de Madri, Russo e Irina. As CCEs envolvem ações de proteção à organização e os PAs dessa metacontingência são o sucesso em manter a organização na clandestinidade e evitar ações policiais. As consequências culturais que podem selecionar a recorrência de tais CCEs são a aprovação e apoio de outros líderes da organização, dos clientes, além do reconhecimento e respeito por parte de outros criminosos em busca por consultoria voltada para o de tráfico de pessoas.

A Figura 5 apresenta a Metacontingência 4, referente ao Tráfico de Crianças para Adoção Ilegal. As CCEs dessa metacontingência podem ser divididas em dois grupos, de acordo com seus agentes: as CCEs que envolvem os traficantes, principalmente Wanda e Lívia, que adquiriam crianças para fornecer a casais estrangeiros, e as CCEs que envolvem as vítimas do tráfico de crianças que buscavam suas famílias biológicas, sendo Aisha e sua família os principais personagens. A jovem Aisha, foi um bebê sequestrado por Wanda e vendido para a mãe adotiva. $\mathrm{O}$ PA das primeiras CCEs é o grande número de crianças vítimas do tráfico, com consequências culturais em forma de lucro para a organização criminosa, com aprovação por parte dos clientes/consumidores. No entanto, o PA das CCEs das vítimas do tráfico que procuram por suas famílias é o reencontro entre as crianças adotadas ilegalmente e suas famílias biológicas. Entre as consequências culturais estão o apoio da mídia ao relatar o sucesso de algumas famílias que atuavam em rede à procura de seus familiares desparecidos, apoio dos operadores da lei, com o aprimoramento de leis de proteção às crianças e alertas contra ações criminosas do tráfico de pessoas.

A metacontingência teve a função de apresentar à audiência que a adoção ilegal pode ser um aspecto do tráfico de pessoas, apesar de não estar inclusa no Protocolo Adicional à Convenção das Nações Unidas contra a Criminalidade Organizada Transnacional relativo à Prevenção, à Repressão e à Punição do Tráfico de Pessoas, em especial de Mulheres e Crianças (UNODC, 2000). Também não é prevista no Decreto-lei $\mathrm{n}^{\circ} 2.848$ de 7 de dezembro de 1940 ou na Lei no 11.106 de 26 de março de 2005 do Código Penal Brasileiro. A decisão de conectar os

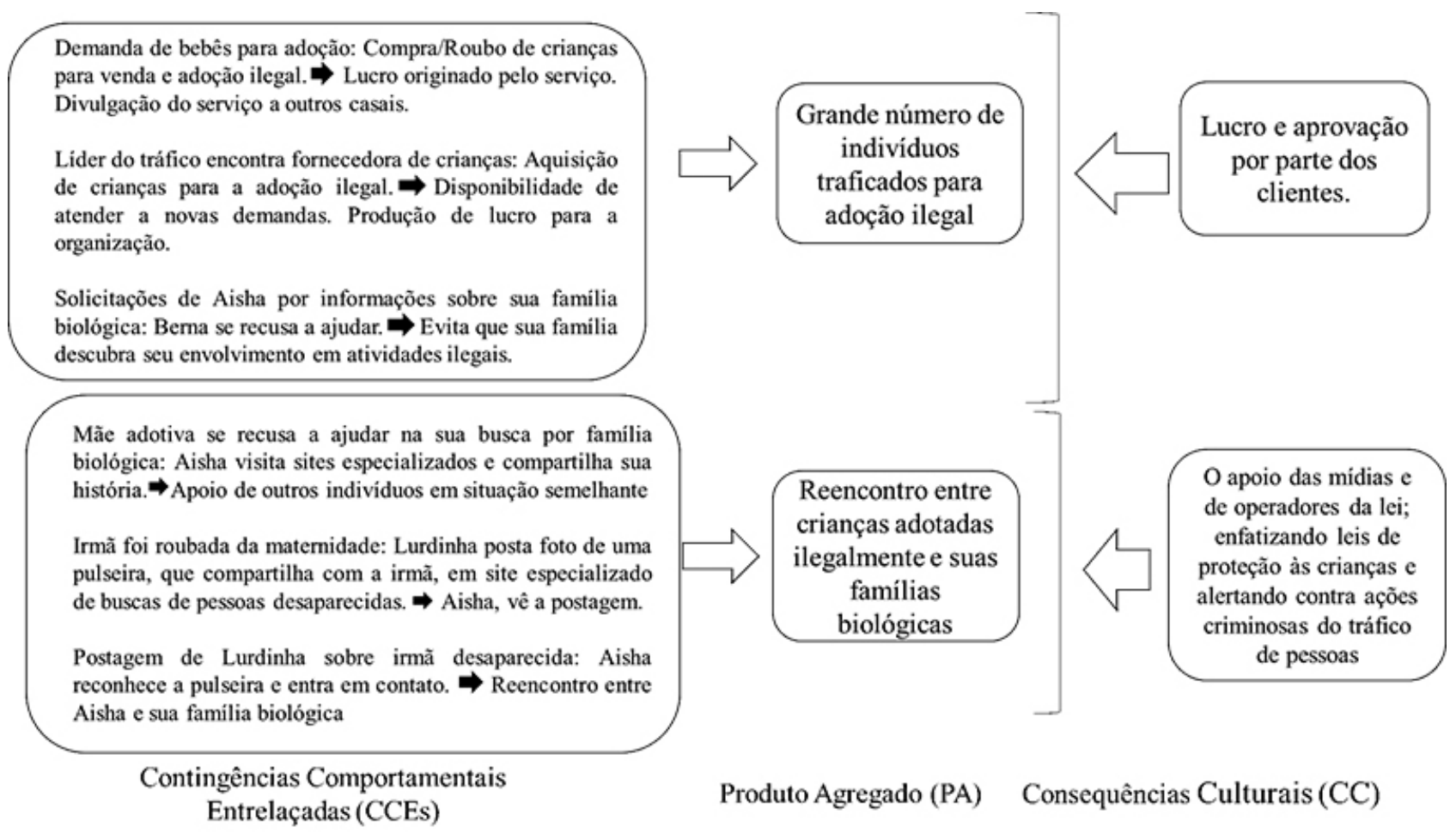

Figura 5. Metacontingência 4 - Tráfico de crianças para adoção ilegal. 
dois crimes pode ter sido influenciada pelo Projeto de Lei nº49 (Senado Federal, 2012), que inclui, no Art. 154-C, a adoção ilegal na definição do crime de tráfico de pessoas.

A Figura 6 apresenta a Metacontingência 7, a qual se refere a ações de controle do tráfico de pessoas. Seus principais agentes são indivíduos que trabalham diretamente com o setor de justiça: entre os personagens estão os policiais Heloisa, Ricardo, Barros e Joyce e os advogados Stênio, Haroldo e Deborah. As CCEs dessa metacontingência envolvem ações investigativas para o combate ao crime de tráfico de pessoas tais como a infiltração em outra instituição criminosa, uma boate em Istambul, e a investigação de identidades falsas da aliciadora. Os PAs dessa metacontingência são a extinção desta organização de tráfico de pessoas; apreensão dos participantes no crime de tráfico de pessoas; resgate das vítimas; reconhecimento por parte da população; e fortalecimento da lei contra o crime de tráfico de pessoas. A divulgação das mídias sobre as ações policiais compõe essas consequências culturais e potencializa os efeitos das CCEs $\rightarrow$ PAs dessa metacontingência.

A Metacontingência 7 teve a função principal de utilizar seus agentes, especialmente o personagem da delegada Heloísa, para fornecer informações relevantes, de forma instrucional, sobre o crime de tráfico de pessoas ao público. Assim, a grande equipe de operadores da lei discutiu quem são as vítimas do tráfico de pessoas; a diferença entre tráfico de pessoas e imigração ilegal e o lucro anual da modalidade criminosa. Essas e outras informações relacionadas evocam comportamentos de prevenção e combate ao tráfico de pessoas por parte de outros personagens, assim como pela audiência da obra de ficção Salve Jorge.

A Figura 7 mostra o impacto da discussão do tema tráfico de pessoas sobre a sociedade brasileira, antes, durante e após a exibição da telenovela. Observa-se uma baixa ocorrência de notícias veiculadas em 2011, anterior à exibição da novela. Entretanto, houve um aumento na ocorrência de publicação de notícias durante o ano de 2012 seguido de diminuição na ocorrência de publicação de notícias durante o primeiro semestre de 2013. Porém, a ocorrência se mantém mais alta comparada ao período anterior à novela (Ministério da Justiça, 2014).

Em relação às denúncias registras pela Central de Atendimento à Mulher (Ligue 180), observa-se que, no período anterior à novela, em 2012, registrou-se uma baixa ocorrência de denúncias. Durante o mesmo período do ano de 2013, em que a novela estava sendo exibida por cinco meses, registrou-se um aumento na ocorrência de denúncias. E, no período posterior à exibição da novela, em 2014, houve uma diminuição na ocorrência de denúncias, porém, permanecendo mais alta que o período anterior à novela. Em 2015, dois anos após a exibição da novela, observa-se um novo aumento na ocorrência de denúncias, mostrando as mais altas frequências de denúncias (Secretaria de Política para as Mulheres, 2012, 2013, 2015a, 2015b).

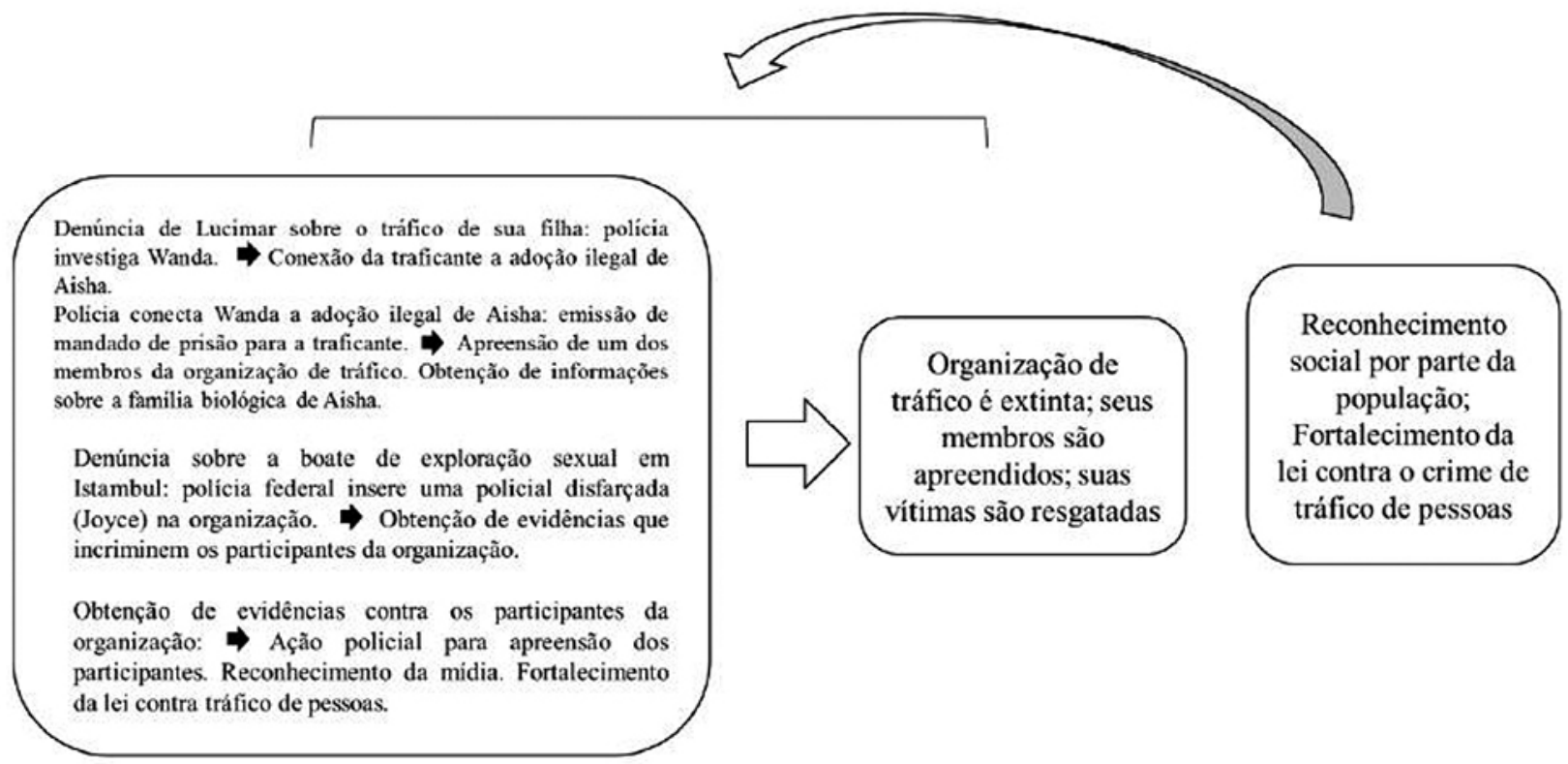

\section{Contingências Comportamentais Entrelaçadas (CCEs)}

Produto Agregado (PA) Consequências Culturais (CC)

Figura 6. Metacontingência 7 - Ações dos operadores da lei. 


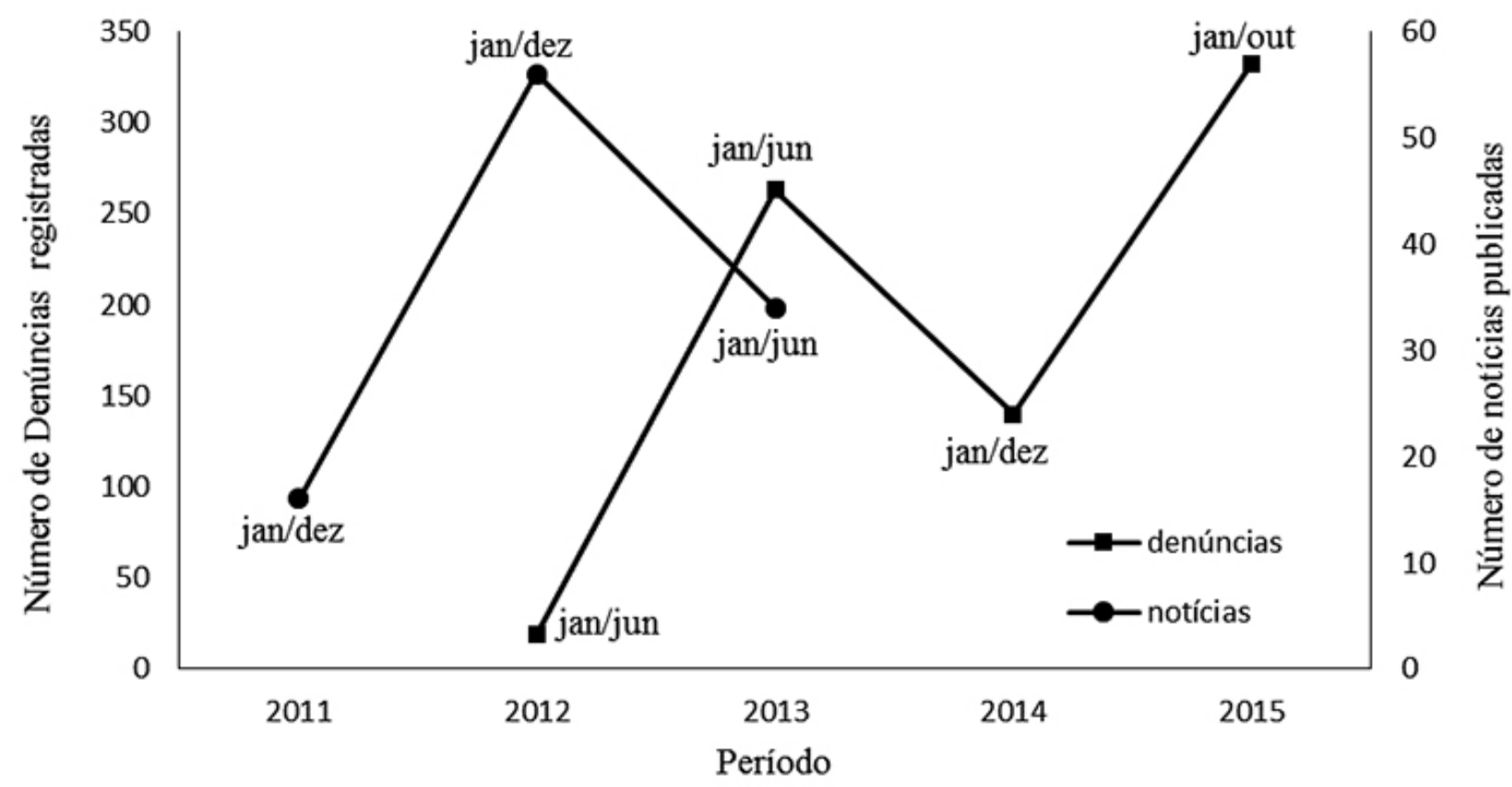

Figura 7. Número de denúncias de tráfico de pessoas registradas pela Central de Atendimento à Mulher entre 2012-2015 (Secretaria de Política para as Mulheres, 2012, 2013, 2015a, 2015b) e número de notícias publicadas sobre tráfico de pessoas (Ministério da Justiça, 2014).

\section{DISCUSSÃO}

A descrição dos eventos a partir do conceito de metacontingência como unidade de análise favoreceu a identificação e classificação das interações entre personagens nas cenas dedicadas ao tráfico de pessoas. Foi possível identificar todos os elementos das metacontingências, isto é, CCEs, PAs e CSQs culturais. A categorização das interações em metacontingências facilitou a identificação das funções de cada uma, dentro do merchandising social, ou seja, de quais mensagens específicas buscava-se transmitir com aquele arranjo de personagens e interações.

As Metacontingências 1, 2 e 3 tiveram por função principal desmistificar o crime do tráfico de pessoas para o público, fornecendo para a audiência informações sobre esses grupos de tráfico e seus possíveis modus operandi (ofertas de emprego no exterior). Esse procedimento é importante, pois conforme foi citado previamente, a falta de conhecimento sobre o tráfico de pessoas contribui para a manutenção e desenvolvimento desse crime, assim como para a baixa frequência de denúncias (Arruda et al., 2013; D’Urso et al., 2013).

A Metacontingência 4 trouxe para mídia a discussão sobre as diferentes finalidades do tráfico de pessoas, conectando esse crime a outro, como adoção ilegal. Dessa forma, a novela discutiu PAs de forma indireta como as alterações legislativas propostas pelo Projeto de Lei n ${ }^{\circ} 479$ (Senado Federal, 2012). A Metacontingência 6 apresentou o sofrimento de vítimas e familiares derivado desse crime, aproximando ficção e realidade ao trazer depoimentos de casos ocorridos no país. A Metacontingência 7 forneceu modelos de contingências comportamentais entrelaçadas de forma a instruir a população e oferecer sugestões de repertórios comportamentais para controle do crime de tráfico de pessoas.

A apresentação do tema em uma novela, por meio de merchandising social, contribui para a construção social do conhecimento sobre tráfico de pessoas na população, uma vez que se torna desnecessário o contato direto com as contingências para que se adquira comportamentos de enfrentamento (Guerin, 1992) ou para aprender repertórios discriminativos em relação a esse crime. Vale ressaltar que, além da divulgação de informações (conhecimento) sobre um tema de alto impacto social, foram apresentadas contingências e metacontingências, isto é, consequências para os comportamentos individuais e para a seleção de produções agregadas em entrelaçamentos de contingências comportamentais envolvendo grande número de pessoas. Portanto, o ponto principal ao se pretender mudar comportamentos em larga escala, nesse caso, envolvendo uma grande audiência, é utilizar-se de programação de consequências para os comportamentos alvo.

Ademais, a novela promoveu discussões sobre o tema tanto pela mídia, quanto pela sociedade em geral, por meio das redes sociais, favorecendo ainda mais que os novos modelos comportamentais aprendidos a partir da novela pudessem atingir um público cada vez maior. O comportamento verbal pode agilizar a mudança de CCEs de forma a otimizar a obtenção de consequências culturais (Costa, Nogueira, \& Vasconcelos, 2012). A partir 
da Figura 7, observou-se uma correlação entre a exibição da novela (outubro de 2012 a maio de 2013) e o aumento da veiculação de notícias em grandes jornais do país e de denúncias feitas ao Ligue 180, sugerindo que apresentação do tema social na novela pode ter contribuído para a mudança das práticas de combate a esse crime, ou seja, o aumento de denúncias pela população.

Entretanto, é importante considerar que a apresentação do tema na novela Salve Jorge teve simultaneidade com dois outros eventos. De julho de 2012 a janeiro de 2013, duas operações da política federal - Brasil e Espanha se unem no combate ao tráfico de mulheres (Portal Brasil, 2012) e PF faz operação contra tráfico de pessoas entre Salvador e Espanha (2013) - desfizeram quadrilhas envolvidas com o tráfico e exploração sexual de mulheres na Espanha. Além disso, o lançamento do II Plano Nacional de Enfrentamento ao Tráfico de Pessoas, com sugestões de ações a serem implementadas pelo governo brasileiro para o combate e prevenção do crime de tráfico de pessoas, por meio de políticas públicas integradas (Ministério da Justiça, 2013), entre outras ações governamentais acerca do crime de tráfico de pessoas, ocorreu durante o primeiro semestre de 2013, quando a novela Salve Jorge estava em seus últimos capítulos (Ministério da Justiça, 2014). Portanto, é possível que não somente a novela, mas também esses eventos tenham contribuído para a veiculação de notícias e de denúncias. E, uma segunda interpretação é que a obra de ficção e seus efeitos sobre a grande audiência tenha composto uma metacontingência com esses PAs em 2013 (e.g., II Plano Nacional de Enfrentamento ao Tráfico de Pessoas).

A pesquisa desenvolvida forneceu, portanto, evidências do potencial da ferramenta merchandising social na mudança de padrões comportamentais na sociedade, conforme observado no estudo de Schiavo (2002) que correlacionou a exibição da novela Laços de Família, em 2001, com o aumento do número de doadores de sangue e de medula no Instituto de Hematologia e no Instituto Nacional do Câncer, respectivamente. Schiavo (2007) demonstrou que a inclusão de temáticas socialmente relevantes como planejamento familiar, métodos anticoncepcionais, saúde da mulher, entre outros, na novela Páginas da Vida, em 2007, auxiliou telespectadoras a modificarem seus comportamentos em relação a esses temas. Jesus (2013) cita também a contribuição da novela Cheias de Charme, exibida em 2012, para a discussão sobre os direitos das empregadas domésticas e a formalização dessa modalidade de trabalho. A autora sugere correlação entre a discussão promovida pela novela e a promulgação da Proposta de Emenda à Constituição $n^{\circ} 79 / 2013$, conhecido como PEC das domésticas. Observa-se, portanto, uma história de intervenções bem-sucedidas utilizando o merchandising social. Essas e outras intervenções referentes a temáticas de impacto social foram aplicadas em novelas da Rede Globo ao longo da década de 2000, promovendo mudanças comportamentais como descritas por Schiavo $(2002,2007)$ e Jesus (2013), de forma análoga a um procedimento de linha de base múltipla, ao mostrarem a eficácia da inclusão de cenas socioeducativas apresentadas pela emissora Rede Globo de Televisão.

Entretanto, é importante considerar os alertas de Ali (2008) sobre a promoção e manutenção do status quo, com a utilização de merchandising social. A novela Salve Jorge criou um contexto que evocou comportamentos por parte da audiência, esclarecendo sobre o tráfico de pessoas, mas simultaneamente fortaleceu também estigmas sobre a prostituição (equiparando-a à exploração sexual sofrida pelas personagens) e romantizou relacionamentos com características abusivas. Théo e Morena são personagens que exemplificam um relacionamento abusivo. Morena foi uma das jovens traficadas que fugiu e denunciou toda a organização. Em seguida, forma-se o casal Théo e Lívia, o personagem passa a interagir com a líder da organização criminosa, após o rompimento com Morena, desconhecendo a associação com o tráfico de pessoas de sua nova parceira), fortalecendo assim outros macrocomportamentos (práticas culturais) prejudiciais ou de risco para a sociedade.

Ao considerar o impacto de uma obra de ficção em telenovela, vale ressaltar que, para diferentes áreas de conhecimento, a audiência tem possibilidade de exercer controle sobre o que é produzido e exibido pela mídia (ANDI, 2004; Vasconcelos, 2010). Em outras palavras, os consumidores dos produtos das mídias podem funcionar como ambiente selecionador de PAs e CCEs envolvidas no desenvolvimento de novelas e outros programas de entretenimento (ver Wang, Pereira \& Andery, 2016).

Nesse sentido, um estudo analítico-comportamental, utilizando análises de práticas culturais via metacontingências presentes na composição dos capítulos de uma novela, tendo como alvo o tema tráfico de pessoas, pode contribuir na programação de novas intervenções que utilizem merchandising social. A distribuição de diferentes metacontingências no transcorrer dos capítulos; a duração da exibição da novela em horário nobre da televisão brasileira (com altos índices de audiência); o total de capítulos; a quantidade de personagens envolvidos; e os contextos enfatizados (e.g., profissões, ambientes domésticos, trabalho lícito e ilícito) são parâmetros que merecem destaque por parte de diretores ou outros interventores responsáveis pelo planejamento do uso dessa estratégia de mudança de comportamentos em larga escala via mídia televisiva. Descrever os entrelaçamentos comportamentais de uma metacontingência (CCEs), demonstrando os PAs resultantes e o ambiente selecionador ou as consequências culturais para esses culturantes (CCEs $\rightarrow$ PAs) e, ainda, a seleção de CCEs por PAs (e.g., o lucro produzido na boate de exploração também seleciona suas CCEs) contribui para que escritores e diretores apresentem o tema de forma eficiente, selecionando arranjos de contingências que serão mais bem compreendidos pela população, com seus eventos antecedentes e suas consequências relacionadas. As 
interpretações analítico-comportamentais dos fenômenos culturais aqui envolvidos podem potencializar os efeitos da estratégia do merchandising social, compondo dessa forma, uma intervenção cultural com poder de alterar macrocomportamentos (práticas culturais) recorrentes de risco para a sociedade.

\section{REFERÊNCIAS}

Agência de Notícias dos Direitos da Infância. (2004). Remoto controle: Linguagem, conteúdo e participação nos programas de televisão para adolescentes. São Paulo: Cortez.

Ali, N. S. A. (2008). Análise do discurso ideológico do merchandising social (Dissertação de mestrado não publicada). Universidade de São Paulo, São Paulo, SP, Brasil.

Alves, A. C. P. (2006). Mídia e construção social do conhecimento: Atentados terroristas no relato de dois jornais brasileiros (Dissertação de Mestrado não publicada). Pontifícia Universidade Católica de São Paulo, São Paulo, SP.

Arruda, E. S., D’Urso, C. M. J., Kodoma, T. C. D. M., \& Armede, J. F. (2013). Cartilha de enfrentamento ao tráfico de pessoas. São Paulo: Ordem dos Advogados do Brasil.

Baia, F. H., Azevedo, F. F., Segantini, S. M., Macedo, R. P., \& Vasconcelos, L. A. (2015). Efeitos de diferentes magnitudes de consequências individuais e culturais sobre culturantes. Acta Comportamentalia, 23(3), 257-272.

Cabral, M.D.C., \& Todorov, J. C (2015). Contingências e metacontingências no processo legislativo da lei sobre remição da pena pelo estudo. Revista Brasileira de Análise do Comportamento, 11(1), 195-202.

Costa, D., Nogueira, C. P. V., \& Vasconcelos, L. A. (2012). Efectos de la comunicación y las consecuencias culturales en combinaciones de elecciones en un INPDG con cuatro participants. Revista Latinoamericana de Psicología, 44(1), 121-131.

Decreto-lei $^{\circ} 2.848$ de 7 de dezembro de 1940 ou na Lei ${ }^{\circ} 11.106$ de 26 de março de 2005 do Código Penal Brasileiro.

Desidério, P. M. M. (2013). Merchandising social: A dinâmica do termo e sua apropriação pela teledramaturgia. Revista Interamericana de Comunicação Midiática, 12(24), 377-396.

Ferreira, M. (2009). Mídia e produções de subjetividade: O poder da mídia. In Conselho Federal de Psicologia (Org.), Mídia e psicologia: Produção de subjetividade e coletividade ( $2^{\mathrm{a}}$ ed., pp. 133-140). São Paulo: Conselho Federal de Psicologia.

Fonseca, F.N., \& Vasconcelos, L. A. (2013). Práticas culturais em campanhas políticas online - uma análise da campanha presidencial brasileira de 2010 via twitter. Acta Comportamentalia, 21(3), 341-357.

Friedman, T. L. (2009). O mundo é plano (C. Serra, S. Duarte \& B. Casotti, Trads.). São Paulo: Objetiva. (Livro publicado originalmente em 2005)

Giannotti, V. (2009). Mídia e produções de subjetividade: O poder da mídia. In Conselho Federal de Psicologia (Org.), Mídia e psicologia: Produção de subjetividade e coletividade $\left(2^{\mathrm{a}}\right.$ ed., pp. 141-148). São Paulo: Conselho Federal de Psicologia.

Glenn, S. S. (1986). Metacontingencies in Walden Two. Behavior Analysis and Social Action, 5(1 \& 2), 2-8.

Glenn, S. S. (1988). Contingencies and metacontingencies: Toward a synthesis of behavior analysis and cultural materialism. The Behavior Analyst, 1, 161-179.

Glenn, S. S. (2004). Individual behavior, culture and social change. The Behavior Analyst, 27, 133-151.

Glenn, S. S., \& Malagodi, E. F. (1991). Process and content in behavioral and cultural phenomena. Behavior and Social Issues, 1(2), 1-13.

Glenn, S. S., \& Malott, M. E. (2004). Complexity and selection: Implications for organizational change. Behavior and Social Issues, 13(2), 89-106.
Glenn, S. S., Malott, M. E., Andery. M. A. P. A., Benvenuti, M., Hourmanfar, R. A., Sandaker, I., Todorov, J. C., Tourinho, E. Z., \& Vasconcelos, L. A. (2016). Toward consistent terminology in a behaviorist approach to cultural analysis. Behavior and Social Issues, 25, 11-27.

Goulart, A. H. (2018). Adolescência, internet e práticas informacionais (Tese de Doutorado não publicada). Universidade de Brasília, Brasília, DF, Brasil.

Guerin, B. (1992). Behavior analysis and the social construction of knowledge. American Psychologist, 47(11), 1423-1432.

Hamburger, E. (2000). Política e Novela. In E. Humburger \& E. Bucci (Orgs), A TV aos 50. Criticando a televisão brasileira no seu cinquentenário (pp. 25-47). São Paulo: Fundação Perseu Abramo.

Harari, Y. N. (2018). 21 Lições para o século 21 (P. Geiger, Trad.). São Paulo. Companhia das Letras.

Houmafar, R. A., \& Mattaini, M. A. (2018). Leadership and cultural change. Managing future well-being. New York: Routlege

IBOPE reajusta valor do ponto de audiência (2014, 22 de Janeiro). Exame. Recuperado de http://exame.abril.com.br/tecnologia/ noticias/ibope-reajusta-valor-do-ponto-de-audiencia

International Labour Office. (2017). Global estimates of modern slavery: forced labour and forced marriaged. International Labour Office, Geneva. Recuperado de https://www.ilo.org/ wcmsp5/groups/public/@dgreports/@dcomm/documents/ publication/wcms_575479.pdf

Jesus, S. T. T. (2013). Função educativa da telenovela brasileira: do merchandising social à ação socioeducativa em Salve Jorge (Dissertação de Mestrado não publicada). Universidade de São Paulo, São Paulo, SP, Brasil.

Kill, R. F. (2016). Análise de metacontingências da Lei 12.608/12 que define a politica nacional de proteção e defesa civil (Dissertação de Mestrado não publicada). Universidade de Brasília, Brasília, DF.

Lamal, P. A., \& Greenspoon, J. (1992). Congressional metacontingencies. Behavior and Social Issues, 2, 71-81.

Laitinen, R., \& Rakos, R. (1997). Corporate control of media and propaganda: A behavior analysis. In P. A. Lamal (Ed.), Cultural contingencies: Behavior analytic perspectives of cultural practices (pp. 237-267). Westport, CT: Praeger Publisher.

Lopes, M. I. V. (2009). Telenovela como recurso comunicativo. Matrizes, 3(1), 21-47.

Martone, R. C., \& Banaco, R. A. (2005). Comportamento social: A imprensa como agência e ferramenta de controle social. In J. C. Todorov, R. C. Martone, \& M. B. Moreira (Orgs.), Metacontingências: Comportamento, cultura e sociedade (pp. 61-80). Santo André, SP: ESETec.

Ministério da Justiça. (2012). Guia de referência para a rede de enfrentamento ao tráfico de pessoas no Brasil. Recuperado de http://www.justica.gov.br/suaprotecao/traficopessoas/ publicacoes/anexos/cartilhaguiareferencia.pdf

Ministério da Justiça. (2013). II Plano Nacional de Enfrentamento ao Tráfico de Pessoas. Recuperado de https://www.unodc.org/ documents/lpo-brazil/noticias/2013/04/2013-04-08_Folder_ IIPNETP Final.pdf

Ministério da Justiça. (2014). Tráfico de pessoas na imprensa. Recuperado de http://pfdc.pgr.mpf.mp.br/atuacao-e-conteudosde-apoio/publicacoes/trafico-de-pessoas/trafico-de-pessoas-naimprensa-brasileira-reporter-brasil 
United Nations Office of Drugs and Crime. (2000). Protocolo relativo à Prevenção, repressão e punição do tráfico de pessoas, em especial mulheres e crianças. Recuperado de http://www.unodc.org/lpo-brazil/pt/crime/marco-legal.html

Organização Internacional do Trabalho (OIT)

PF faz operação contra tráfico de pessoas entre Salvador e Espanha (2013, 30 de Janeiro). G1. Recuperado de http://g1.globo. com/bahia/noticia/2013/01/pf-fazoperacao-contra-trafico-depessoas-entre-salvador-e-espanha.html

Portal Brasil (2012, 04 de dezembro). Brasil e Espanha se unem no combate ao tráfico de mulheres. Recuperado de http://www. brasil.gov.br/cidadania-e-justica/2013/01/brasil-combatetrafico-de-mulheres-com-parcerias-com-paises-e-instituicoes

Proposta de Emenda à Constituição n ${ }^{\circ}$ 79, de 2013.

Schiavo, M. R. (1998). Merchandising social: Sexualidade e saúde reprodutiva nas telenovelas. Revista Brasileira de Sexualidade Humana, 9(2), 168-183.

Schiavo, M. R. (2002). Merchandising social: As telenovelas e a construção da cidadania. Trabalho apresentado no $25^{\circ}$ Congresso Brasileiro de Ciências da Comunicação, Salvador, BA. Recuperado de http://www.intercom.org.br/papers/ nacionais/2002/congresso2002_anais/2002_NP14SCHIAVO. pdf

Schiavo, M. R. (2007). Merchandising social na telenovela "Páginas da Vida": Impacto nos conhecimentos, atitudes e práticas das telespectadoras assíduas. Trabalho apresentado no $30^{\circ}$ Congresso Brasileiro de Ciências da Comunicação, Santos, SP. Recuperado de http://www.intercom.org.br/papers/ nacionais/2007/resumos/R1037-1.pdf

Secretaria de Política para as Mulheres, Central de Atendimento às Mulheres - Ligue 180 (2012). Balanço semestral 2012. Recuperado de http://www.spm.gov.br/sobre/publicacoes/ publicacoes/2012/balanco-semestral-ligue-180-2012

Secretaria de Política para as Mulheres, Central de Atendimento às Mulheres - Ligue 180. (2013). SPM 10 anos: Políticas pelos direitos das mulheres. Recuperado de http://www.spm.gov. br/sobre/publicacoes/publicacoes/2013/balanco-ligue-180janeiro-a-junho-2013

Secretaria de Política para as Mulheres, Central de Atendimento às Mulheres - Ligue 180. (2015a). Balanço 2014. Recuperado de http://www.spm.gov.br/central-de-conteudos/publicacoes/ publicacoes/2015/balanco180_2014-versaoweb.pdf

Secretaria de Política para as Mulheres, Central de Atendimento às Mulheres - Ligue 180. (2015b). Balanço $1^{\circ}$ Semestre 2015. Recuperado de http://www.spm.gov.br/assuntos/ violência/ligue-180-central-de-atendimento-a-mulher/ balanco1sem2015-versao-final.pdf

Senado Federal. (2012). Projeto de Lei $N^{o}$ 479: Dispõe sobre prevenção e punição de tráfico interno e internacional de pessoas, bem como medidas de proteção a vítima. Recuperado de http://www.senado.leg.br/atividade/rotinas/materia/getPDF. asp?t=121385\&tp=1
Sénéchal-Machado, V., \& Todorov, J.C. (2008). A travessia na faixa de pedestres em Brasília (DF/Brasil): Exemplo de uma intervenção cultural. Revista Brasileira de Análise do Comportamento, 4(2), 191-204.

Singhal, A., Cody, M. J., Rogers, E. M., \& Sabido, M. (2008). Entertainment - Education and social change. History, Research, and Practice. Mahwah, NJ: Routledge. (Livro original publicado em 2004)

Soares, P. F. R., Rocha, A. P. M. C., Guimarães, T. M. M., Leite, F. L., Andery, M. A. P. B., \& Tourinho, E. Z. (2018). Effects of verbal and non-verbal cultural consequence. Behavior and Social Issues, 27, 31-46.

Skinner, B. F. (2003). Ciência e comportamento humano (11 a ed., J. C. Todorov \& R. Azzi, Trads.) São Paulo: Martins Fontes. (Trabalho original publicado em 1953)

Todorov, J. C. (2017). Conservation and transformation of cultural practices through contingencies and metacontingencies. In J. C. Todorov (Org.), Trends in Behavior Analysis (Vol. 1). Recuperado de https://itunes.apple.com/us/book/trends-inbehavior-analsis/id1143256280?Is $=1 \& \mathrm{mt}=11$

Tourinho, E. Z., \& Vichi, C. (2012). La investigación analíticoconductual de la selección cultural y la complejidad de los fenómenos culturales. Revista Latinoamericana de Psicologia, 44, 169-179.

Vasconcelos, L. A. (2010). Práticas culturais envolvendo a criança e a mídia: Interface entre a Comunicação e a Análise do Comportamento. In M. M. C. Hübner, M. R. Garcia, P. R. Abreu, E. N. P. Cillo, \& P. B. Falerios (Orgs.), Sobre comportamento e cognição. Análise experimental do comportamento, cultura, questões conceituais e filosóficas (pp. 129-136). Santo André, SP: ESETec.

Vasconcelos, L. A. (2013). Explorando macrocontingencias and metacontingencias: Contribuciones experimentales y noexperimentales. Suma Psicológica, 20(1) 31-43.

Venson, A. M., \& Pedro, J. M. (2013). Tráfico de pessoas: Uma história do conceito. Revista Brasileira de História, 33(65), 61-83.

Vasconcelos, L. A., \& Lemos, R. F. (2018). Do sistema teórico de B. F. Skinner à metacontingência: Observação, Experimentação e Interpretação. Revista Brasileira de Análise do Comportamento, 14(1), 79-90.

Vasconcelos, L. A., Nogueira, V. G. C., Vieira, P. A., \& Henz, G. P. (no prelo). A behavioral systems approach to cultural interventions: Focusing on aggregate products for the web of interactions. Behavior and Social Issues.

Vichi, C., Andery, M.A. P. A., \& Glenn, S. S. (2009). A metacontingency experiment: The effects of contingent consequences on patterns of interlocking contingencies of reinforcement. Behavior and Social Issues, 18, 41-57.

Wang, M. L., Pereira, M. E. M., \& Andery, M. A. (2016). Mídia, comportamento e cultura. Perspectivas em Análise do Comportamento, 7(2), 147-164. 